Jurnal Mahasiswa BK An-Nur : Berbeda, Bermakna, Mulia

Volume 7 Nomor 3 Tahun 2021

Tersedia Online: https://ojs.uniska-bjm.ac.id/index.php/AN-NUR

p-ISSN. 2460-9722 | e-ISSN. 2622-8297

\title{
HUBUNGAN ANTARA KONFORMITAS DAN KEPERCAYAAN DIRI DENGAN PERILAKU KONSUMTIF YANG TERJADI PADA ANGGOTA KOMUNITAS VANSHEAD KENDAL
}

\author{
Ahmad Fahmi Rijal ${ }^{1}$, Laelatul Anisah², Mochamad Widjanarko³ \\ ${ }^{1}$ Universitas Selamat Sri \\ ${ }^{2}$ Universitas Selamat Sri \\ ${ }^{3}$ Universitas Muria Kudus \\ E-mail: laelatulanisah89@gmail.com/No. HP 08112512511
}

\begin{abstract}
ABSTRAK
Penelitian ini bertujuan untuk mengetahui hubungan antara konformitas dan kepercayaan diri dengan perilaku konsumtif yang terjadi pada anggota komunitas Vanshead Kendal, hubungan antara konformitas dan perilaku konsumtif, hubungan antara kepercayaan diri dan perilaku konsumtif, dan besarnya sumbangan efektif konformitas dan kepercayaan diri terhadap perilaku konsumtif. Subjek penelitian berjumlah 63 orang anggota komunitas Vanshead Kendal yang dipilih secara purposive sampling. Pengumpulan data menggunakan kuesioner perilaku konsumtif, konformitas, dan kepercayaan diri. Hasil pengujian dengan menggunakan analisis regresi dua predictor menunjukkan $R x 1 x 2 y=0,361$ dengan $\mathrm{F}=4,496$ dan $p=0,000(p<0,01)$. Artinya ada hubungan yang sangat signifikan antara konformitas dan kepercayaan diri dengan perilaku konsumtif. Hipotesis minor satu dan dua diuji menggunakan teknik korelasi product moment. Hasil uji hipotesis minor satu menunjukkan adanya hubungan positif antara konformitas dengan perilaku konsumtif, dimana nilai $r x l y=0,346$ dan $p=0,000 \quad(p<0,01)$. Pada uji hipotesis minor dua menunjukkan adanya hubungan negatif antara kepercayaan diri dengan perilaku konsutif, dimana nilai $r x 2 y=-0,183$ dan $p=0,000(p<0,01)$. Penelitian ini juga menunjukkan nilai $R$ square konformitas dan kepercayaan diri sebesar 0,130 . Artinya konformitas dan kepercayaan diri mempengaruhi perilaku konsumtif yang terjadi pada anggota komunitas Vanshead Kendal sebesar $13 \%$, sisanya $87 \%$ dipengaruhi oleh faktor lain.
\end{abstract}

Kata kunci : konformitas, kepercayaan diri, perilaku konsumtif

\begin{abstract}
This study aims to determine the relationship between conformity and self-confidence with consumptive behavior that occurs in members of the Vanshead Kendal community, the relationship between conformity and consumptive behavior, the relationship between self-confidence and consumptive behavior, and the magnitude of the effective contribution of conformity and self-confidence to consumptive behavior. The research subjects were 63 members of the Vanshead Kendal community who were selected by purposive sampling. Collecting data using a questionnaire of consumptive behavior, conformity, and self-confidence. The test results using two predictor regression analysis showed Rx1x2y $=0.361$ with $F=4.496$ and $p=0.000(p<0.01)$. This means that there is a very significant relationship between conformity and self-confidence with consumptive behavior. The first and second minor hypotheses were tested using the product moment correlation technique. The results of the first minor hypothesis test showed a positive relationship between conformity and consumptive behavior, where the value of rxly $=0.346$ and $p=0.000$ ( $p<0.01)$. In the second minor hypothesis test, there is a negative relationship between self-confidence and consumptive behavior, where the value of rx $2 y=-0.183$ and $p=0.000$ ( $p<0.01)$. This study also shows the $R$ square value of conformity and self-confidence of 0.130. This means that conformity and self-confidence affect consumptive behavior that occurs in members of the Vanshead Kendal community by $13 \%$, the remaining $87 \%$ is influenced by other factors.
\end{abstract}

Keywords: conformity, self-confidence, consumptive behaviour

Dipublikasikan Oleh :

UPT Publikasi dan Pengelolaan Jurnal

Universitas Islam Kalimantan Muhammad Arsyad Al-Banjari Banjarmasin 
Ahmad Fahmi Rijal ${ }^{1}$, Laelatul Anisah ${ }^{2}$, Mochamad Widjanarko ${ }^{3}$ Jurnal Mahasiswa BK An-Nur : Berbeda, Bermakna, Mulia

Volume 7 Nomor 3 Tahun 2021

Tersedia Online: https://ojs.uniska-bjm.ac.id/index.php/AN-NUR p-ISSN. 2460-9722 | e-ISSN. 2622-8297

\section{PENDAHULUAN}

Manusia pada dasarnya adalah makhluk tuhan yang setiap waktu mengalami perkembangan. Perkembangan sendiri adalah suatu proses dimana adanya perubahan yang dimulai sejak masa pembuahan dan terus berlangsung selama hidup manusia (Santrock, 2012). Proses perkembangan yang tidak hanya melibatkan individu saja mengharuskan seseorang untuk bisa bergaul dan beradaptasi dengan lingkungan sekitar serta berusaha menemukan jati ditinya sendiri. Salah satu langkah realistis yang dilakukan adalah ikut bergabung dalam suatu komunitas atau kelompok sosial tertentu. Kelompok sosial adalah suatu himpunan atau kesatuan manusia yang hidup bersama, karena ada hubungan diantara mereka (Soekanto dan Sulistyowati, 2014). Balqiah dan Setyowardhani (2017) menjelaskan kelompok sebagai dua orang atau lebih yang berinteraksi selama periode waktu tertentu untuk mencapai sasaran perseorangan maupun sasaran bersama. Berdasarkan tingkat organisasinya, kelompok terbagi menjadi 2, yaitu kelompok formal dan kelompok informal.

Salah satu kelompok informal yang ditemui adalah Vanshead Kendal. Komunitas ini secara garis besar merupakan sebuah perkumpulan atau himpunan orang-orang yang memiliki hobi dan kecintaan yang sama, yaitu sebuah brand bernama Vans. Didalam komunitas ini terdapat sebuah struktur organisasi, norma atau aturan, dan daftar nama anggota yang secara keseluruhan tidak tertulis. Oleh karena itu berdasarkan penjabaran yang dijelaskan oleh Balqiah dan Setyowardhani (2017), komunitas Vanshead Kendal masuk kedalam kelompok informal, dimana sebuah perkumpulan yang memiliki tujuan yang sama namun kurang terstruktur dan kurang terorganisasi. Tidak menutup kemungkinan dalam suatu perkumpulan atau kelompok muncul beberapa kendala dan permasalahan yang terjadi selama kurun waktu yang tidak menentu.

Dari data lapangan yang diperoleh peneliti, perilaku konsumtif yang terjadi pada angota komunitas Vanshead Kendal umumnya disebabkan oleh adanya rasa tidak percaya diri dan tingginya tingkat ikut-ikutan atau konformitas kepada rekan sesama anggota. Berita terbaru yang diterbitkan oleh Detik.com pada hari Sabtu, 14 Desember 2019 dengan judul "Antrean Membludak, Perilisan Sneakers Compass Dibatalkan", menunjukkan tingginya tingkat perilaku konsumtif yang terjadi pada remaja masa kini (Ngantung, 2019). Isi dari berita tersebut menggambarkan antusias yang ditunjukkan oleh para pencari barang langka yang akan dirilis. Bahkan mereka rela datang semalam sebelum hari perilisan dibuka, walaupun pada akhirnya perilisan produk tersebut ditunda karena kondisi yang tidak memungkinkan, mengingat produk yang akan dirilis hanya berjumlah 240 pasang. Sedangkan konsumen yang mengantre sudah membludak dari semalam sebelum hari perilisan tiba.

Konsumsi dilakukan oleh semua manusia untuk memenuhi kebutuhan baik berupa primer maupun sekunder (Astuti, 2013). Kurniawan (2017) menambahkan bahwa pada kenyataannya banyak dari mereka yang terlalu berlebihan dalam mengkonsumsi suatu produk bahkan cenderung mengarah pada perilaku konsumtif. Permasalahan yang sering terjadi adalah konsumsi secara berlebihan dengan tujuan untuk memenuhi kebutuhan tersier bukan kebutuhan primer maupun sekunder. Lubis (dalam Octaviani dan Kartasasmita, 2017) mendefinisikan perilaku konsumtif sebagai perilaku yang tidak lagi didasarkan pada pertimbangan yang rasional, melainkan karena keinginan yang sudah mencapai taraf tidak rasional lagi. Perkembangan zaman yang sangat pesat ikut terlibat dalam hal ini, misalnya pakaian yang pada awalnya digunakan untuk menutupi tubuh kini sudah beralih fungsi sebagai gaya dan mode (Octaviani dan Kartasasmita, 2017).

Menurut Sumartono (dalam Wati dan Suyanto, 2016) perilaku konsumtif adalah membeli barang tanpa pertimbangan rasional atau bukan atas dasar kebutuhan pokok. Tidak jarang seseorang merasa kekurangan dalam kebutuhan pokoknya, namun sanggup untuk memenuhi kebutuhan yang sifatnya bukan kebutuhan pokok (Chartrand dan Fitzsimons, 2010). Sementara Fromm (dalam Pratama, 2017) menjelaskan bahwa perilaku konsumtif sebagai keinginan yang terus meningkat untuk mendapatkan kepuasan dalam hal kepemilikan barang dan jasa tanpa memperdulikan kegunaan, hanya berdasarkan keinginan untuk membeli yang lebih baru, lebih banyak, dan lebih bagus dengan tujuan menunjukkan status. Perilaku konsumtif adalah sebuah keinginan berlebih untuk terus memenuhi kebutuhannya baik kebutuhan primer, sekunder, ataupun tersier (Suparti, 2016). Seseorang tidak dapat membedakan antara ketiga kebutuhan tersebut, sehingga pada akhirnya kebutuhan tersebut dianggap sama dan harus terpenuhi ketiganya. Perilaku konsumtif tidak hanya terjadi pada orang dengan golongan menengah keatas, namun dari kalangan kebawah pun sudah banyak yang melakukan pembelian berlebihan dan menjurus pada perilaku konsumtif (Victor, dkk, 2018).

Dipublikasikan Oleh : 
Ahmad Fahmi Rijal ${ }^{1}$, Laelatul Anisah ${ }^{2}$, Mochamad Widjanarko ${ }^{3}$ Jurnal Mahasiswa BK An-Nur : Berbeda, Bermakna, Mulia

Volume 7 Nomor 3 Tahun 2021

Tersedia Online: https://ojs.uniska-bjm.ac.id/index.php/AN-NUR

p-ISSN. 2460-9722 | e-ISSN. 2622-8297

Menurut Kotler (dalam Haryani dan Herwanto, 2015) faktor yang mempengaruhi perilaku konsumtif ada 4, yaitu 1) faktor kebudayaan yang terdiri dari budaya, sub-budaya, dan kelas sosial, 2) faktor sosial yang terdiri dari kelompok acuan, keluarga, serta peran dan status, 3) faktor pribadi yang meliputi usia, tahapan dalam siklus hidup, pekerjaan, keadaan ekonomi, gaya hidup, konsep diri, serta kepribadian, dan 4) faktor psikologis yang meliputi motivasi, persepsi, pengetahuan, keyakinan dan sikap. Faktorfaktor tersebut kemudian memunculkan adanya beberapa aspek yang terkandung dalam perilaku konsumtif. Sumartono (dalam Wati dan Suyanto, 2016) menyebutkan bahwa aspek dari perilaku konsumtif ada 8, yaitu 1) membeli produk karena iming-iming hadiah, 2) membeli produk karena kemasannya menarik, 3) membeli produk demi menjaga penampilan diri dan gengsi, 4) membeli produk atas pertimbangan harga (bukan atas dasar manfaat atau kegunaannya), 5) membeli produk hanya sekedar menjaga simbol status, 6) memakai produk karena unsur konformitas terhadap model yang mengiklankan, 7) munculnya penilaian bahwa membeli produk dengan harga mahal akan menimbulkan rasa percaya diri yang tinggi, dan 8) mencoba lebih dari dua produk sejenis (merk berbeda).

Salah satu faktor yang memperngaruhi perilaku konsumtif adalah konformitas. Konformitas menurut Berk (dalam Pratama, 2017) merupakan suatu hal yang paling banyak terjadi pada fase remaja. Konformitas dapat memunculkan berbagai perilaku, diantaranya adalah gaya bahasa, sikap, nilai sosial yang akan diikuti, dan nilai-nilai yang berkaitan dengan penampilan diri. Berdasarkan pengertian tersebut, konformitas memang banyak berpengaruh dalam kehidupan seseorang, salah satunya dalam perilakunya untuk membeli suatu produk yang cenderung mengarah kepada perilaku konsumtif.

Javanmard dan Mohammadi (2015) mendefinisikan konformitas sebagai perubahan perilaku atau kepercayaan seseorang akibat pengaruh dan tekanan dari kelompok. Tekanan yang muncul ini dapat mempengaruhi seseorang karena adanya kekuatan dari orang yang memberikan tekanan kepada seseorang agar bisa sesuai dengan kelompok dimana ia sedang berada. Sedangkan Davidoff (dalam Haryani dan Herwanto, 2015) mendefinisikan konformitas sebagai bentuk perubahan perilaku atau sikap akibat dari tekanan baik secara nyata maupun tidak nyata. Konformitas adalah upaya penyesuaian diri yang dilakukan oleh seseorang agar bisa diterima dalam suatu kelompok (Kurniawan, 2017). Konformitas bisa terjadi karena adanya perasaan cemas dan tertekan apabila ia tidak sesuai dengan lingkungan yang ada. Menurut Sears (dalam Nurfadiah dan Yulianti, 2017) konformitas sendiri terdiri dari 3 aspek, yaitu 1) kekompakan, 2) kesepakatan, dan 3) ketaatan.

Selain konformitas, faktor lain yang dapat mempengaruhi perilaku konsumtif adalah kepercayaan diri. Kepercayaan diri menurut Hakim (dalam Nurfadiah dan Yulianti, 2017) merupakan suatu keyakinan yang kuat untuk bisa berbuat segala sesuatu dengan memanfaatkan kelebihannya. Seseorang pada umumnya akan melakukan segala sesuatu yang dianggap menguntungkan bagi dirinya dan terlebih dapat meningkatkan kepercayaan dirinya. Kepercayaan diri adalah keyakinan untuk melakukan sesuatu pada diri subjek sebagai karakteristik pribadi yang di dalamnya terdapat keyakinan akan kemampuan diri, optimis, objektif, bertanggung jawab, rasional, dan realistis (Ghufron dan Risnawita, 2012). Seseorang yang memiliki kepercayaan diri tinggi biasanya dapat bergaul dengan baik di lingkungan dimana ia berada. Karena sejatinya ia percaya akan kemampuan yang ia miliki.

Kumara (dalam Ghufron dan Risnawita, 2012) mendefinisikan kepercayaan diri sebagai ciri kepribadian yang mengandung arti keyakinan terhadap kemampuan diri sendiri. Willis (dalam Ghufron dan Risnawita, 2012) menjelaskan bahwa kepercayaan diri adalah keyakinan bahwa seseorang mampu menanggulangi suatu masalah dengan situasi terbaik dan dapat memberikan sesuatu yang menyenangkan bagi orang lain. Rombe (2014) dalam penelitiannya menyebutkan bahwa subjeknya merasa khawatir akan dianggap kudet dan kurang update ketika tidak memiliki barang yang sedang trendy. Hal itulah yang menyebabkan seseorang bersikap untuk lebih konsumtif. Lauster (dalam Ghufron dan Risnawita, 2012) menyebutkan bahwa kepercayaan diri terdiri dari 5 aspek, yaitu 1) keyakinan kemampuan diri, 2) optimis, 3) objektif, 4) bertanggung jawab, serta 5) rasional dan realistis.

\section{METODE}

Subjek dari penelitian ini berjumlah 63 orang yang berasal dari anggota komunitas Vanshead Kendal. Pengambilan sampel menggunakan teknik purposive sampling dengan kriteria yang digunakan sampel adalah anggota aktif di komunitas Vanshead Kendal, sampel bebas boleh perempuan atau laki-laki, sampel sedang tinggal di Kendal, dan sampel

Dipublikasikan Oleh :

UPT Publikasi dan Pengelolaan Jurnal

Universitas Islam Kalimantan Muhammad Arsyad Al-Banjari Banjarmasin 
Ahmad Fahmi Rijal ${ }^{1}$, Laelatul Anisah ${ }^{2}$, Mochamad Widjanarko ${ }^{3}$ Jurnal Mahasiswa BK An-Nur : Berbeda, Bermakna, Mulia

Volume 7 Nomor 3 Tahun 2021

Tersedia Online: https://ojs.uniska-bjm.ac.id/index.php/AN-NUR

p-ISSN. 2460-9722 | e-ISSN. 2622-8297

memiliki waktu luang untuk pelaksanaan penelitian. Data yang diperoleh dalam penelitian ini menggunakan kuesioner perilaku konsumtif, kusioner konformitas, dan kuesioner kepercayaan diri.

Dasar pembuatan kuesioner perilaku konsumtif sesuai dengan aspek perilaku konsumtif yang dikemukakan oleh Sumartono (dalam Wati dan Suyanto, 2016). Aspek perilaku konsumtif meliputi; 1) membeli produk karena iming-iming hadiah, 2) membeli produk karena kemasannya menarik, 3) membeli produk demi menjaga penampilan diri dan gengsi, 4) membeli produk atas pertimbangan harga (bukan atas dasar manfaat atau kegunaannya), 5) membeli produk hanya sekedar menjaga simbol status, 6) memakai produk karena unsur konformitas terhadap model yang mengiklankan, 7) munculnya penilaian bahwa membeli produk dengan harga mahal akan menimbulkan rasa percaya diri yang tinggi, dan 8) mencoba lebih dari dua produk sejenis (merk berbeda). Dasar pembuatan kuesioner konformitas sesuai dengan aspek konformitas yang dikemukakan oleh Sears (dalam Nurfadiah dan Yulianti, 2017). Aspek konformitas meliputi; 1) kekompakan, 2) kesepakatan, dan 3) ketaatan. Sedangkan dasar pembuatan kuesioner kepercayaan diri sesuai dengan aspek kepercayaan diri yang dikemukakan oleh Lauster (dalam Ghufron dan Risnawita, 2016). Aspek kepercayaan diri meliputi; keyakinan kemampuan diri, optimis, objektif, bertanggung jawab, dan rasional dan realistis.

Teknik analisis dalam penelitian ini menggunakan teknik analisis regresi dua prediktor dan teknik korelasi product moment dengan bantuan Statistical Product and Service Solution (SPSS) 23.0 for windows.

\section{HASIL DAN PEMBAHASAN}

\section{Uji Normalitas}

Uji normalitas terhadap variabel perilaku konsumtif, konformitas, dan kepercayaan diri yang dilakukan dengan teknik Kolmogorov-SmirnovZ pada program SPSS 23.00 for Windows menunjukkan sebaran data NORMAL, dimana $P=$ $0,982(p>0,05)$.

\section{Uji Linieritas}

Uji linieritas hubungan pada penelitian ini terdiri dari dua hasil, dimana hasil pertama bertujuan untuk mengetahui hubungan antara perilaku konsumtif dengan konformitas, sedangkan hasil kedua bertujuan untuk mengetahui hubungan antara perilaku konsumtif dengan kepercayaan diri. Uji linieritas hubungan pertama yang diukur menggunakan teknik ANOVA pada program SPSS 23.00 for Windows menunjukkan adanya hubungan antara variabel perilaku konsumtif dan konformitas, dimana $F_{\text {Hitung }}=0,418$ dan $p=0,981(p>0,05)$. Uji linieritas hubungan kedua yang diukur menggunakan teknik ANOVA pada program SPSS 23.00 for Windows menunjukkan adanya hubungan antara variabel perilaku konsumtif dan kepercayaan diri, dimana $F_{\text {Hitung }}=0,846$ dan $p=$ $0,624(p>0,05)$.

\section{Uji Multikolinieritas}

Uji Multikolinieritas dilakukan untuk menguji model regresi apakah ditemukan adanya hubungan antara variabel bebas 1 dan variabel bebas 2 . Model regresi yang baik selayaknya tidak terjadi multikolinieritas. Uji multikolinieritas pada penelitian ini menggunakan bantuan program SPSS 23.00 for Windows dengan teknik Regresi berganda dan menggunakan metode VIF (Variance Inflation Factor). Hasil uji multikolinieritas antar variabel bebas (Konformitas dan Kepercayaan Diri) menunjukkan tidak terjadinya multikolinieritas, karena nilai tolerance kedua variabel bebas bernilai 0,954 $(>0,1)$ dan nilai VIF kedua variabel bebas bernilai $1,048(<10)$.

\section{Uji Hipotesis}

\section{A. Hipotesis Mayor}

Hasil uji hipotesis mayor yang dilakukan dengan teknik korelasi Analisis regresi dua predictor pada program SPSS 23.00 for Windows menunjukkan adanya hubungan yang sangat signifikan antara variabel perilaku konsumtif dengan konformitas dan kepercayaan diri pada anggota komunitas Vanshead Kendal, dimana koefisiensi dari ketiga variabel $R_{x I x 2 y}=0,361$ dengan $F_{\text {Hitung }}=4,496\left(F_{\text {Hitung }}>3,150\right)$ dan $P=$ $0,000(p<0,01)$. Dengan demikian hipotesis mayor yang diajukan dalam penelitian ini diterima.

\section{B. Hipotesis Minor Satu}

Hasil uji hipotesis minor satu yang dilakukan dengan teknik korelasi Product Moment pada program SPSS 23.00 for Windows menunjukkan adanya hubungan positif yang sangat signifikan antara variabel perilaku konsumtif dengan konformitas, dimana koefisien korelasi kedua variabel $R_{x l y}=0,346$ dengan $P=0,000(p<0,01)$. Artinya semakin tinggi konformitas maka semakin

Dipublikasikan Oleh :

UPT Publikasi dan Pengelolaan Jurnal

Universitas Islam Kalimantan Muhammad Arsyad Al-Banjari Banjarmasin 
Ahmad Fahmi Rijal ${ }^{1}$, Laelatul Anisah ${ }^{2}$, Mochamad Widjanarko ${ }^{3}$ Jurnal Mahasiswa BK An-Nur : Berbeda, Bermakna, Mulia

Volume 7 Nomor 3 Tahun 2021

Tersedia Online: https://ojs.uniska-bjm.ac.id/index.php/AN-NUR p-ISSN. 2460-9722 | e-ISSN. 2622-8297

tinggi pula perilaku konsumtif yang terjadi pada anggota komunitas Vanshead Kendal. Begitu pula sebaliknya, semakin rendah konformitas maka semakin rendah pula perilaku konsumtif yang terjadi pada anggota komunitas Vanshead Kendal. Dengan begitu hipotesis minor satu yang diajukan pada penelitian ini diterima.

\section{Hipotesis Minor Dua}

Hasil uji hipotesis minor dua yang dilakukan dengan teknik korelasi Product Moment pada program SPSS 23.00 for Windows menunjukkan adanya hubungan negatif yang sangat signifikan antara variabel perilaku konsumtif dengan kepercayaan diri, dimana koefisien korelasi kedua variabel $R_{x l y}=-0,175$ dengan $P=0,000(p<0,01)$. Artinya semakin tinggi kepercayaan diri maka semakin rendah perilaku konsumtif yang terjadi pada anggota komunitas Vanshead Kendal. Begitu pula sebaliknya, semakin rendah kepercayaan diri maka semakin tinggi perilaku konsumtif yang terjadi pada anggota komunitas Vanshead Kendal. Dengan begitu hipotesis minor dua yang diajukan pada penelitian ini diterima.

\section{Pembahasan}

Berdasarkan hasil analisis diatas dapat diketahui bahwa $R_{\mathrm{x} 1 \times 2 \mathrm{y}}=0,361$ dengan $\mathrm{F}=4,496$ dan $p=0,000(p<0,01)$ dengan persamaan regresi yaitu $\mathrm{Y}=60,177+0,287 \mathrm{x}_{1}+(-0,183) \mathrm{x}_{2}$, ini berarti ada hubungan yang sangat signifikan antara konformitas dan kepercayaan diri dengan perilaku konsumtif pada anggota komunitas Vanshead Kendal. Adapun penjelasan dari persamaan regresi diatas menunjukkan jika konfomitas dan kepercayaan diri nilainya adalah 0 , maka perilaku konsumtif nilainya adalah 60,177. Koefisien regresi variabel konformitas sebesar 0,287 artinya jika variabel bebas lain nilainya tetap dan variabel konformitas nilainya mengalami kenaikan $1 \%$, maka perilaku konsumtif akan mengalami kenaikan sebesar 60,177. Koefisien regresi konformitas bernilai positif artinya terjadi hubungan positif yang sangat signifikan antara konformitas dengan perilaku konsumtif. Semakin tinggi konformitas, maka semakin tinggi pula tingkat perilaku konsumtif yang terjadi. Sedangkan pada koefisien regresi kepercayaan diri memiliki nilai sebesar $(-0,183)$. Artinya jika variabel bebas lain nilainya tetap dan kepercayaan diri nilainya mengalami kenaikan sebesar $1 \%$, maka perilaku konsumtif akan mengalami penurunan sebesar 60,177. Koefisien regresi kepercayaan diri bernilai negatif artinya terjadi hubungan negatif yang sangat signifikan antara kepercayaan diri dengan perilaku konsumtif. Semakin tinggi kepercayaan diri, maka semakin rendah tingkat perilaku konsumtif yang terjadi.

Hasil uji hipotesis pertama dalam pengolahan data menunjukkan adanya nilai koefisien korelasi $r_{\mathrm{x} 1 \mathrm{y}}=0,346$ dengan $p=0,000(p<0,01)$. Hal ini menunjukkan bahwa ada hubungan positif yang sangat signifikan antara variabel konformitas dengan perilaku konsumtif. Artinya semakin tinggi tingkat konformitas maka semakin tinggi pula tingkat perilaku konsumtif yang terjadi. Begitu pula sebaliknya, semakin rendah tingkat konformitas maka semakin rendah pula tingkat perilaku konsumtif yang terjadi. Dengan demikian hipotesis minor satu yang diajukan dalam penelitian ini dapat diterima.

Hal ini sesuai dengan pernyataan oleh Djuwitaningsih (2019) dimana ia menjelaskan bahwa fenomena yang sering muncul dalam lingkungan sekarang adalah adanya usaha pemenuhan keinginan dengan tanpa mempertimbangkan akibat-akibat yang menyertainya, terutama hubungan dengan potensi ekonomi. Mallinson dan Hatemi (2018) menambahkan bahwa pembentukan perilaku konsumtif dan keputusan untuk membeli suatu produk secara luas dapat dikaitkan dari dua faktor, yaitu internal dan eksternal. Faktor internal dalam diri seseorang mencakup self-esteem, konsep diri, motivasi, harga diri, dan proses belajar. Sedangkan faktor eksternal mencakup teman sebaya dan masyarakat.

Hasil pengolahan data yang dilakukan sesuai dengan penelitian yang dilakukan oleh Fitriyani, dkk (2013) dengan judul "Hubungan Antara Konformitas dengan Perilaku Konsumtif pada Mahasiswa di Genuk Indah Semarang" menunjukkan hasil adanya hubungan positif antara kedua variabel tersebut. Tingkat efektifitas konformitas yang dihasilkan untuk mempengaruhi perilaku konsumtif pada penelitian tersebut sebesar $10,9 \%$ dan sisanya $89,1 \%$ nya disebabkan oleh faktor lain.

Hasil uji hipotesis kedua dalam pengolahan data menunjukkan adanya nilai koefisien korelasi $r_{\mathrm{x} 2 \mathrm{y}}=(-0,183)$ dengan $p=0,000(p<0,01)$. Hal ini menunjukkan bahwa ada hubungan negatif yang signifikan antara variabel kepercayaan diri dengan perilaku konsumtif. Artinya semakin tinggi tingkat kepercayaan diri maka semakin rendah tingkat perilaku konsumtif yang terjadi. Begitu pula

Dipublikasikan Oleh :

UPT Publikasi dan Pengelolaan Jurnal

Universitas Islam Kalimantan Muhammad Arsyad Al-Banjari Banjarmasin 
Ahmad Fahmi Rijal ${ }^{1}$, Laelatul Anisah ${ }^{2}$, Mochamad Widjanarko ${ }^{3}$ Jurnal Mahasiswa BK An-Nur : Berbeda, Bermakna, Mulia

Volume 7 Nomor 3 Tahun 2021

Tersedia Online: https://ojs.uniska-bjm.ac.id/index.php/AN-NUR p-ISSN. 2460-9722 | e-ISSN. 2622-8297

sebaliknya, semakin rendah tingkat kepercayaan diri maka semakin tinggi tingkat perilaku konsumtif yang terjadi. Dengan demikian hipotesis minor dua yang diajukan dalam penelitian ini dapat diterima.

Hasil tersebut sesuai dengan penelitian terdahulu oleh Rombe (2014) dengan judul "Hubungan Body Image dan Kepercayaan Diri dengan Perilaku Konsumtif pada Remaja Putri di SMA Negeri 5 Samarinda" menunjukkan adanya hubungan signifikan dan saling mempengaruhi antara ketiga variabel tersebut. Dengan taraf koefisien sebesar 0,598 menggambarkan adanya hubungan positif dan tingginya tingkat kepercayaan diri yang secara langsung memberikan kontribusi terhadap perilaku konsumtif dengan angka presentase sebesar $35,77 \%$.

Hasil pengolahan data sesuai dengan pernyataan Ghufron dan Risnawita (2012), dimana ia menjelaskan bahwa kepercayaan diri adalah

\section{Tabel 1}

Sumbangan Efektif (SE) Variabel Konformitas dan Kepercayaan Diri dengan Perilaku Konsumtif pada Anggota Komunitas Vanshead Kendal

\begin{tabular}{cc}
\hline Keterangan & Sumbangan Efektif \\
\hline Konformitas & $11,2 \%$ \\
\hline Kepercayaan Diri & $1,8 \%$ \\
\hline Total & $13 \%$
\end{tabular}

Hasil penelitian juga mendeskripsikan bagaimana tingkat perilaku konsumtif, konformitas, dan kepercayaan diri yang terjadi pada anggota komunitas Vanshead Kendal.

Tabel 2

Statistik Deskriptif Hasil Penelitian Descriptive Statistics

\begin{tabular}{lccc}
\hline & Mean & Std. Deviation & N \\
\hline Perilaku Konsumtif & 63,97 & 9,11 & 63 \\
\hline Konformitas & 57,83 & 10,26 & 63 \\
\hline Kepercayaan Diri & 69,9 & 5,229 & 63 \\
\hline
\end{tabular}

Dari tabel diatas dapat diketahui nilai mean (rata-rata) variabel perilaku konsumtif sebesar 63,97 konformitas sebesar 57,83 dan kepercayaan diri sebesar 69,9 dengan nilai standar deviasi masing-masing variabel yang sudah dibulatkan yaitu menjadi 9, 10 dan 5. Berdasarkan nilai mean (rata-rata) dan standar deviasi, nilai tersebut kemudian digunakan untuk membagi hasil penelitian menjadi 3 kategori, yaitu tinggi, sedang, dan rendah. Rumus yang digunakan untuk mengetahui kategori ini menggunakan pedoman yang telah dikemukakan oleh Azwar (2015).

Dipublikasikan Oleh :

UPT Publikasi dan Pengelolaan Jurnal

Universitas Islam Kalimantan Muhammad Arsyad Al-Banjari Banjarmasin 
Ahmad Fahmi Rijal ${ }^{1}$, Laelatul Anisah ${ }^{2}$, Mochamad Widjanarko ${ }^{3}$ Jurnal Mahasiswa BK An-Nur : Berbeda, Bermakna, Mulia

Volume 7 Nomor 3 Tahun 2021

Tersedia Online: https://ojs.uniska-bjm.ac.id/index.php/AN-NUR p-ISSN. 2460-9722 | e-ISSN. 2622-8297

Tabel 3

Rumus Kategosisasi Hasil Penelitian

\begin{tabular}{cccc}
\hline \multirow{2}{*}{ Kategorisasi } & \multicolumn{3}{c}{ Rumus Yang Digunakan } \\
\cline { 2 - 4 } & Perilaku Konsumtif & Konformitas & Kepercayaan Diri \\
\hline Rendah & $\mathrm{X}<54$ & $\mathrm{X}<47$ & $\mathrm{X}<65$ \\
\hline Sedang & $54 \leq \mathrm{X} \leq 72$ & $47 \leq \mathrm{X} \leq 67$ & $65 \leq \mathrm{X} \leq 74$ \\
\hline Tinggi & $\mathrm{X}>72$ & $\mathrm{X}>67$ & $\mathrm{X}>74$ \\
\hline
\end{tabular}

Tabel 4

Kategorisasi Hasil Penelitian

\begin{tabular}{ccccccc}
\hline \multirow{2}{*}{ Keterangan } & \multicolumn{2}{c}{ Perilaku Konsumtif } & \multicolumn{2}{c}{ Konformitas } & \multicolumn{2}{c}{ Kepercayaan Diri } \\
\cline { 2 - 7 } & $\mathbf{F}$ & $\mathbf{\%}$ & $\mathbf{F}$ & $\boldsymbol{\%}$ & $\mathbf{F}$ & $\mathbf{\%}$ \\
\hline Rendah & 7 & $11,1 \%$ & 8 & $12,7 \%$ & 10 & $15,9 \%$ \\
\hline Sedang & 43 & $68,3 \%$ & 51 & $81,0 \%$ & 47 & $74,6 \%$ \\
\hline Tinggi & 13 & $20,6 \%$ & 4 & $6,3 \%$ & 6 & $9,5 \%$ \\
\hline Total & 63 & $100 \%$ & 63 & $100 \%$ & 63 & $100 \%$ \\
\hline
\end{tabular}

Hasil penelitian menunjukkan bahwa tingkat perilaku konsumtif, konformitas, dan kepercayaan diri yang terjadi pada anggota komunitas Vanshead Kendal berada pada kategori sedang.

Penelitian ini masih terdapat beberapa kelemahan. Adapun beberapa kemungkinan yang menyebabkan penelitian ini mengalami banyak kelemahan diantaranya adalah:

a. Penyebaran kuesioner melalui Google Form yang masih asing di hadapan responden membuat mereka sedikit kebingungan tentang perintah yang diberikan, sehingga banyak dari mereka hanya mengisi satu kuesioner sebelum akhirnya diberikan instruksi lanjutan.

b. Kesibukan masing-masing responden yang berbeda-beda membuat peneliti harus bersabar menunggu respon dari kuesioner yang telah disebarkan.

c. Efek pandemic yang mengakibatkan peneliti dan responden tidak diperbolehkan untuk bertatap muka, sehingga dalam pengisian kuesioner penelitian, peneliti tidak dapat memantau secara langsung.

\section{PENUTUP}

Ada hubungan antara konformitas dan kepercayaan diri dengan perilaku konsumtif yang terjadi pada anggota komunitas Vanshead Kendal. Hal itu ditunjukkan oleh nilai koefisiensi dari ketiga variabel, yaitu $R_{x I x 2 y}=0,361$ dengan $F_{\text {Hitung }}=4,496$ $\left(F_{\text {Hitung }}>3,150\right)$ dan $P=0,000 \quad(p<0,01)$. Ada hubungan positif antara konformitas dan perilaku konsumtif yang terjadi pada anggota komunitas Vanshead Kendal. Hal itu ditunjukkan oleh nilai koefisien korelasi pada variabel konformitas dan perilaku konsumtif yang bernilai 0,346. Artinya semakin tinggi tingkat konformitas maka semakin tinggi pula tingkat perilaku konsumtif yang terjadi pada anggota komunitas Vanshead Kendal. Begitu pula sebaliknya, semakin rendah tingkat konformitas maka semakin rendah pula tingkat perilaku konsumtif yang terjadi pada anggota komunitas Vanshead Kendal. Ada hubungan negatif antara kepercayaan diri dengan perilaku konsumtif yang terjadi pada anggota komunitas Vanshead Kendal. Hal itu ditunjukkan oleh nilai koefisien korelasi pada variabel kepercayaan diri dan perilaku konsumtif yang bernilai $(-0,175)$. Artinya semakin tinggi tingkat kepercayaan diri maka semakin rendah tingkat perilaku konsumtif yang terjadi pada anggota komunitas Vanshead Kendal. Begitu pula sebaliknya, semakin rendah tingkat kepercayaan diri maka semakin tinggi tingkat perilaku konsumtif yang terjadi pada anggota komunitas Vanshead Kendal.

Presentase Sumbangan Efektif (SE) yang diberikan oleh variabel konformitas dan kepercayaan diri terhadap variabel perilaku konsumtif sebesar

Dipublikasikan Oleh :

UPT Publikasi dan Pengelolaan Jurnal

Universitas Islam Kalimantan Muhammad Arsyad Al-Banjari Banjarmasin 
Ahmad Fahmi Rijal ${ }^{1}$, Laelatul Anisah ${ }^{2}$, Mochamad Widjanarko ${ }^{3}$ Jurnal Mahasiswa BK An-Nur : Berbeda, Bermakna, Mulia

Volume 7 Nomor 3 Tahun 2021

Tersedia Online: https://ojs.uniska-bjm.ac.id/index.php/AN-NUR p-ISSN. 2460-9722 | e-ISSN. 2622-8297

$13 \%(R$ square $=0,130)$, dimana konformitas sebesar $11,2 \%\left(\beta_{x 1}=0,323\right)$ dan kepercayaan diri sebesar $1,8 \%\left(\beta_{\mathrm{x} 2}=(-0,105)\right)$.

\section{REFERENSI}

Astuti. Endang Dwi. (2013). Perilaku Konsumtif dalam Membeli Barang pada Ibu Rumah Tangga di Kota Samarinda. eJournal Psikologi, 1(2), 148156.

Azwar, S. (2015). Penyusunan Skala Psikologi. (Edisi 2. Cetakan ke-8) Yogyakarta: Pustaka Pelajar.

Balqiah, T. E., \& Setyowardhani, H. (2017). Perilaku Konsumen. (Cetakan ke-12) Tanggerang Selatan: Universitas Terbuka.

Chartrand, T. L., \& Fitzsimons, G, J. (2010). Nonconscious Consumer Psychology. Journal of Consumer Psychology, 12(1), 1-3.

Djuwitaningsing, E. W. (2019). Perubahan Perilaku Konsumtif dan Gaya Hidup Tenaga Kerja Wanita (TKW) Purna, Jurnal Sosial Politik Humaniora, 7(1), 1-21.

Fitriyani, N., Widodo. P. B., \& Fauziah. N. (2013). Hubungan Antara Konformitas dengan Perilaku Konsumtif pada Mahasiswa di Genuk Indah Semarang. Jurnal Psikologi Undip, 12(1), 55-68.

Ghufron, M. N., \& Risnawita, R. S. (2012). Teoriteori Psikologi. (Cetakan ke-3). Jogjakarta: ArRuzz Media.

Haryani, I., \& Herwanto, J. (2015). Hubungan Konformitas dan Kontrol Diri dengan Perilaku Konsumtif terhadap Produk Kosmetik pada Mahasiswi. Jurnal Psikologi, 11(1), 5-11.

Javanmard, G. H., \& Mohammadi. R. (2015). The Relationship of Conformity and Memory. Journal of Educational, Health, and Community Psychology, 4(2), 2088-3129.

Kurniawan. Chandra. (2017). Analisis Faktor-faktor yang Mempengaruhi Perilaku Konsumtif Ekonomi pada Mahasiswa. Jurnal Media Wahana Ekonomika, 13(4), 107-118.
Mallinson. D. J., \& Hatemi. P. K. (2018). The Effect of Information and Social Conformity on Opinion Change. Journal PLOS ONE, 10(1), 1-22.

Ngantung, D. (2019). Antrean Membludak, Perilisan Sneakers Compass Dibatalkan. Jakarta: Detik.com Web: https://m.detik.com/wolipop/fashionnews/d-4822592/antrean-membludak-perilisansneakers-compass-dibatalkan diakses pada tanggal 26 Maret 2020 Pukul 13.45 WIB.

Nurfadiah, R. T., \& Yulianti, A. (2017). Konformitas dengan Kepercayaan Diri pada Remaja Komunitas Pecinta Korea di Pekanbaru. Psikoislamedia Jurnal Psikologi, 2(2), 212-223.

Octaviani, C., \& Kartasasmita, S. (2017). Pengaruh Konsep Diri Terhadap Perilaku Konsumtif Pembelian Produk Kosmetik pada Wanita Dewasa Awal. Jurnal Muara Ilmu Sosial, Humaniora, dan Seni, 1(2), 126-133.

Pratama, H. S. (2017). Hubungan Konformitas dengan Perilaku Konsumtif terhadap Merchandise Liverpool pada Anggota Suporter Klub Sepakbola Liverpool di Bekasi. Jurnal Psikologi, 10(2), 138148.

Rombe, S. (2014). Hubungan Body Image dan Kepercayaan Diri dengan Perilaku Konsumtif pada Remaja Putri di SMA Negeri 5 Samarinda. ejournal Psikologi, 2(1), 76-91.

Santrock, J. W. (2012). Life-Span Development. (Edisi ke-13 Jilid 1) Terjemahan oleh Benedictine Widyasinta. Jakarta: Erlangga.

Soekanto, S., \& Sulistyowati, B. (2014). Sosiologi Suatu Pengantar. (Edisi Revisi. Cetakan ke-46) Depok: Raja Grafindo Persada.

Suparti. (2016). Mitigating Consumptive Behaviour: The Analysis of Learning Experiences of Housewives. International Educational Studies, $9(3), 114-122$

Victor, V., Throppan, J. J., Nathan, R. J., \& Maria, F. F. (2018). Factor Influencing Consumer Behaviour and Prospective Purchase Decision in a Dinamic Pricing Environment - an Exploratory Factor Analysis Approach. Journal Social Science, 7(153), 1104-1117.

Dipublikasikan Oleh :

UPT Publikasi dan Pengelolaan Jurnal

Universitas Islam Kalimantan Muhammad Arsyad Al-Banjari Banjarmasin 
Ahmad Fahmi Rijal ${ }^{1}$, Laelatul Anisah ${ }^{2}$, Mochamad Widjanarko ${ }^{3}$ Jurnal Mahasiswa BK An-Nur : Berbeda, Bermakna, Mulia Volume 7 Nomor 3 Tahun 2021

Tersedia Online: https://ojs.uniska-bjm.ac.id/index.php/AN-NUR p-ISSN. 2460-9722 | e-ISSN. 2622-8297

Wati, M. Y., \& Suyanto, T. (2016). Faktor yang Mendorong Perilaku Konsumtif Siswa SMA di Surabaya. Jurnal Kajian Moral dan Pendidikan, $1(4), 107-121$.

Dipublikasikan Oleh :

UPT Publikasi dan Pengelolaan Jurnal

Universitas Islam Kalimantan Muhammad Arsyad Al-Banjari Banjarmasin 